\title{
Influence of Photoperiod and Shelter on Some Phenotypic Traits in African Catfish (Clarias gariepinus Burchell 1822) Larvae
}

\author{
Ahmed Saud Alsaqufi', Sheikh Mustafizur Rahman ${ }^{2,3 *}$, Roshmon Thomas Mathew ${ }^{2}$, \\ Yousef Ahmed Alkhamis ${ }^{1,2}$, Md. Moshiur Rahman ${ }^{3,4}$ and Muhammed Aslam Pathiri ${ }^{2}$ \\ ${ }^{1}$ Agriculture and Food Sciences College, King Faisal University, Hofuf-420, Zip 31982, \\ Al-Ahsa, Kingdom of Saudi Arabia. \\ ${ }^{2}$ Fish Resources Research Center, King Faisal University, Hofuf-420, Al-Ahsa, Zip \\ 31982, Kingdom of Saudi Arabia \\ ${ }^{3}$ Fisheries and Marine Resource Technology Discipline, Khulna University, \\ Khulna-9208, Bangladesh \\ ${ }^{4}$ Tokyo University of Marine Science and Technology, Tokyo, Japan
}

\section{A B S T R A C T}

Photoperiod and shelter have direct or indirect effects on phenotypic traits expression in different fish species. The present study was, therefore, intended to explore whether these light and shelter could influence some phenotypic traits of African catfish larvae under laboratory condition. Newly hatched larvae were stocked in plastic aquaria $(10 \mathrm{~L})$ at a rate of 5 individuals $/ \mathrm{L}$ and reared for one month under four treatments such as $24 \mathrm{~h}$ light (24L), $24 \mathrm{~h}$ dark (24D), 12h light and 12h dark with PVC (12DL PVC), and $12 \mathrm{~h}$ light and $12 \mathrm{~h}$ dark without PVC (12DL) conditions. A total of 108 larvae were sampled for phenotypic traits analysis. The results revealed that complete darkness (24D) significantly improved the overall growth parameters (total length, standard length, caudal peduncle length, anal fin length, caudal fin length, total body depth, dorsal fin length, pre dorsal distance, pre anal distance, pre ventral distance, head width, head length, eye diameter, maxillary barbell length, inter orbital length, and specific growth rate) than all other treatments, while no significant variation was found among other treatments. Although shelter did not show any significant role in the overall growth, it significantly reduced the larval mortality than those reared without shelter. The survival rates were also significantly different among various light regimes in which the highest was found in 24D (86\%) followed by 12DL PVC (74\%), 24L (71\%), and $12 \mathrm{DL}(60 \%)$. The study also revealed that larvae reared in $24 \mathrm{D}$ exhibited maximum dark brown body colouration (63\%), while in $24 \mathrm{~L}$ showed maximum light brown colouration $(96 \%)$. On the other hand, maximum larvae were appeared as medium brown color (76\%) in tanks having PVC, whereas many of them were light brown (61\%) in non-PVC tanks. Taken together, the study suggests that $C$. gariepinus larvae should be reared in completely dark condition to enhance their overall production.
\end{abstract}

\begin{tabular}{l} 
Article Information \\
Received 07 May 2020 \\
Revised 30 June 2020 \\
Accepted 20 July 2020 \\
Available online 20 November 2020 \\
Authors' Contribution \\
\hline ASA Conceptualization, supervision, \\
project administration and fund \\
acquisition. SMR Conceptualization, \\
methodology, investigation, data \\
curation, writing-original draft, \\
visualization. RTM Conceptualization, \\
software, investigation, writing-review \\
and editing data, visualization. YA \\
Supervision, project administration. \\
MMR Formal analysis, data curation, \\
writing-review and editing. MAP \\
Investigation, resources. \\
Key words \\
Growth, SGR, Survival, Body \\
colouration, PVC pipe
\end{tabular}

\section{INTRODUCTION}

$\mathrm{P}$ hotoperiod works as a Zeitgeber (cue or synchronizer), controlling regular endogenous rhythms in fish (Simensen et al., 2000). In most cases, photoperiod regulates fish growth, social behaviour, metabolic rates, locomotion, sexual maturation, survival, reproduction and body pigmentation (colouration) (Duston and Saunder, 1990; Silva-Garcia, 1996; Boeuf and Bail, 1999; Boeuf and Falco, 2001; Trippel and Neil, 2002; Biswas and Takeuchi, 2002; Biswas et al., 2002, 2005; Mendonça et al., 2009). Being an environmental stimulus, the photoperiod is

\footnotetext{
* Corresponding author: mustafizfrmt@yahoo.com, srahman@kfu.edu.sa 0030-9923/2021/0001-0001 \$ 9.00/0

Copyright 2021 Zoological Society of Pakistan
}

connected to the light length period over a day. The intensity and increase of this 'light time' takes place in accordance with the types of weather and seasons of the locality (Bromage et al., 2001). The photoperiod, in association with other synchronizers (e.g. temperature, salinity, habitat, shelter, dissolved oxygen, $\mathrm{pH}$, water level, etc.), can influence the biological rhythm (circadian and/or annual) of animals, and thereby affecting food utilization, weight, energy allocation, movement, and other physiological factors as well (Biswas and Takeuchi, 2002). According to Almazán-Rueda et al. (2005), photoperiod requirements are species-specific and differ for every developmental phase. Dark and light rotation is, in general, regarded as the key synchronizer of feeding movement (Hossain et al., 1999). While photoperiod may influence larval stages (e. g. growth) positively, juvenile stages remain unaffected (Barlow et al., 1995). However, 
photoperiod has no influence on growth and metabolic rates for yellowtail flounder (Purchase et al., 2000), halibut (Hallaråker et al., 1995), and turbot (Imsland et al., 1995).

Photoperiod manipulation is a common and effective practice in order to acquire better growth rates, maturation, spawning and accelerated development of larval fish (Mustapha et al., 2014; Brown et al., 2014; Lundova et al., 2019). In case of mature fishes, photoperiod influence has been noticed since there are variations in light dependant circadian rhythimicity, production of melatonin and its secretory rations (Iigo et al., 1991), anatomical and biochemical variations in the pineal organ the prime transducer of the environmental light in fish through melatonin (Srivastava, 2003). Artificial photoperiod regimes are changes in the natural light and dark cycles and any manipulation or modification of environmental factors like temperature or light causes sudden changes in the environment, which may induce stress and ultimately compromise the overall welfare and interests of the fish (Barton and Iwama, 1991; Wendelaar Bonga, 1997). Light intensity offers several crucial benefits such as assisting fish to escape from predators (Talanda et al., 2018), locate feeds for nourishment (Boeuf and Bail, 1999), pursue suitable preys (Granqvist and Mattila, 2004) and discover habitats (Harvey et al., 2012). Moreover, the skin color of certain fishes can be affected by the reflection, absorption and scattering of light by the microstructures and pigments within the fish integument (Leclercq et al., 2010; Sugimoto, 2002).

Refuges or shelters (such as caves, crevices, holes, etc.), another important life regulating physical factor, not only provide protection from currents, predators, competitors, and strong illumination but also provide opportunity for reproduction and foraging (Holbrook and Schmitt, 2002; Johansen et al., 2008). Any species of fish requires particular habitat, which is also a life cycle dependent stage (Beck et al., 2009). Animals use various types of shelter, but the benefits of these are not restricted to the increase in safety or reproduction. Shelter functions as a feeding ground (Moring and Nicholson, 1994; Ishida et al., 2008) and resting place (Johnson and Stein, 1979; Benaka, 1999) for many teleosts. Many intertidal animals use shelters in order to avoid thermal stress and dehydration during arid periods or low tide. For instance, intertidal crabs move to suitable shelter (like burrows, crevices or damp cracks) to decrease the risk of water loss (Nybakken, 1993) while cane toad (Bufo marinus) seeks suitable diurnal shelter to avoid dehydration and temperature stress (Seebacher and Alford, 2002) during dry periods. So far as the Brazilian lizard, Tropidurus torquatus, is concerned, the excess of microhabitats, which helps egg development, affects the duration of the spawning period as low scales of moisture reduce egg viability and decrease embryo dimensions (Wiederhecker et al., 2002). Several studies have shown a positive relationship between shelter and growth in some aquatic animals. For example, mud eel (Monopterus Cuchia) and Asian catfish (Clarias batrachus) grow well in water hyacinth (Narejo et al., 2003; Sahiduzzaman et al., 2018) while estuarine grouper (Epinephelus salmoides) did better in tires of vehicles (Chua and Teng, 1979). In another study, submerged aquatic plants for Penaeus monododn showed the highest growth and survival (Ali et al., 1999).

The influence of photoperiod on growth and survival of African catfish at the larval stage has been observed by a number of authors (Britz and Pienaar, 1992; Appelbaum and McGeer, 1998; Appelbaum and Kamler, 2000; Almazán-Rueda et al., 2004), while Hossain et al. (1988) and Boerrigter et al. (2016) have observed the effect of shelter on survival, growth, aggression and stress of African catfish fingerlings having different outcomes (i.e. positive and negative results). For example, C. gariepinus fingerlings (weight $0.79 \mathrm{gm}$ and length $49 \mathrm{~mm}$ ) stocked in plastic tanks with shelter have had higher growth than without shelter (Hossain et al., 1998) while Boerrigter et al. (2016) did not observe any positive results with shelter materials for the same species (8-10 gm). However, the effects of photoperiod and shelter on the phenotypic plasticity in this species, mainly larval stage, are not well understood. Immediately after hatching, larvae undergo several crucial stages (like yolk sac absorption, fin and head development, burble, eye, pigmentation, etc.) and any sudden changes in environment causes severe abnormalities that reduces the larval quality afterwards. The major constraint for widespread farming of African catfish is poor and highly variable survival of larvae under the fluctuating environmental conditions (De Graaf and Janssen, 1996). In aquaculture systems, light directly affects the quality of egg and fitness of offspring (Endal et al., 2000), development (Boeuf and Bail, 1999), movement (MacPhail et al., 2009), metabolism (Appelbaum and Kamler, 2000) and body colouration (Denson and Smith, 1997). All the above-mentioned aspects are speciesspecific and light intensity-dependent (Tian et al., 2015).

African catfish, C. gariepinus is one of the most well accepted aquaculture fishes at least in twelve African countries (Mathiesen, 2012; Hecht, 2013). The important characteristic features of this species are easy to breed and culture with high stocking densities. Moreover, this fish can tolerate a high range of salinity, low oxygen concentration, high temperature, and most significantly, it offers large profits with minimum production cost (Teugels, 1986; Bovendeur et al., 1987). Despite its limited freshwater supplies, the Kingdom of Saudi Arabia 
(KSA) has emerged as a role model for the development of this species by optimizing the use of water, and high levels of sunlight and temperatures as the ecological conditions in this country are phenomenal. As Saudi Arabia solely depends on marine fish, this species could be an alternative protein source for the nation, and the regular consumption of this fish may reduce the fishing load in the sea. Considering the importance of this species in Saudi Arabia, the Kingdom introduced this species in 1987 from Egypt. However, despite having lots of potentialities, only limited numbers of studies have been conducted considering the local conditions of the middle-east where the desert climate is especially characterized by extreme temperature during summer and very low retaining water capabilities by the land. The use of shelter in fish ponds might provide protection against heat shock as well as ensure the welfare of fish as catfish is nocturnal in nature (Rahman et al., 2014; Britz and Pienaar, 1992; Barriga et $a l ., 2016)$. Therefore, the aim of this study was to evaluate the effect of variable photoperiods in the presence/absence of shelter on some important phenotypes of larvae in African catfish C. gariepinus.

\section{MATERIALS AND METHODS}

\section{Broodstocks maintenance}

Fingerlings (5 to $8 \mathrm{~cm}$ ) were obtained from the research station of King Abdulaziz City and Science Technology (KACST), Al Muzahmiya, Riyadh, KSA and maintained in 5000 tons fiberglass tank with continuous water circulation at the Fish Resources Research Center, King Faisal University, Al Hasa, KSA. Animals were fed commercial pellets (ARASCO Company, KSA) twice daily (35\% protein; $5 \%$ of their body weight) until the evidence of maturation was seen. Three pairs of mature female (1520 to $1744 \mathrm{~g}$ ) and male (1100 to $1350 \mathrm{~g}$ ) broods were selected for this study to obtain experimental larvae.

\section{Induced breeding and incubation}

Spawning to obtain the gametes was induced following the procedure described by Adebayo and Popoola (2008). Briefly, selected mature female and male broods were injected with OvaprimR at a dosage of 0.5 and $1.0 \mathrm{ml} / \mathrm{kg}$ for males and females, respectively and held individually in a separate plastic tank $(600 \mathrm{~L})$ to avoid cannibalism. Ovulation took place fourteen to eighteen $\mathrm{h}$ from the first time of injection. Eggs were obtained in a clean bowl by stripping the female gently along its abdomen. Since sperm of $C$. gariepinus can not be obtained by stripping, testis were collected surgically. Immediately after separation, adhered fat and blood from the testes were removed and testes were cut into small pieces and passed through bolting silk. Artificial insemination was conducted instantly after gamete collection. After mixing with fresh water, fertilized eggs were placed in hatching beds made with nylon mesh and then submerged in glass tanks $(30 \mathrm{~cm}$ depth) with continuous water flow and aeration at room temperature $\left(28-30^{\circ} \mathrm{C}\right)$. Hatching of C. gariepinus larvae occurred $15 \mathrm{~h}$ after artificial insemination at an average temperature of $30^{\circ} \mathrm{C}$.

\section{Photoperiod management}

A total of 600 newly hatched C. gariepinus larvae were randomly distributed into four experimental groups (three replicates per treatment) and stocked in plastic aquaria (10L) for a month to assess the effect of photoperiod and shelter on their phenotypic plasticity. Each treatment group was exposed to four different experimental conditions, i.e. $24 \mathrm{~h}$ light (24L), $24 \mathrm{~h}$ dark (24D), $12 \mathrm{~h}$ light and 12 $\mathrm{h}$ dark with PVC (12DL_PVC), and $12 \mathrm{~h}$ light and $12 \mathrm{~h}$ dark without PVC (12DL). A stand lamp with fluorescent tube lights $80 \mathrm{~lx}$ was installed $15 \mathrm{~cm}$ above the continuous light filtered tanks. The dark tanks were coved with two layers of black polyethylene sheeting $(250 \mathrm{p})$ and placed cardboard box. Remaining tanks were placed in natural photoperiod conditions. In 12DL_PVC treatment, 2 of 6 $\mathrm{cm}$ PVC pipes were used as shelter material.

\section{Larval rearing}

Larvae were stoked in a plastic tank (10L) at a stocking density of $5 \mathrm{~L}^{-1}$ for a month for observation of growth, specific growth rate, survival, body colouration and some other important phenotypic traits (see below) under different photoperiod and shelter conditions. The experimental animals were fed Artemia nauplii until satiation (ad libitum) thrice daily $(0800,1500$ and 2100 h) for the first ten days, and then introduced commercial pelleted feed (ARASCO Company, KSA; 32\% protein; $5 \%$ of their body weight) specially prepared for catfish species larvae. During the entire experimental stage, the water quality parameters stayed optimal. The water quality in the tanks was maintained by applying some measures like siphoning out the bottom debris and waste (leftover food, fecal matter, dead fish, etc) and replacing one-third of the water every alternative morning $(0700 \mathrm{~h})$ prior to feeding.

\section{Phenotypic analysis}

Twenty-seven ( 9 individuals $\times 3$ tanks) larvae were randomly sampled from each treatment for selected phenotypic traits measurement at the final day of the experiment. Collected larvae were euthanized in a $200 \mathrm{ppm}$ benzocaine solution followed by $4 \%$ Davidson fixation (Moore et al., 1953). The selected phenotypic traits of the 
experimental larvae treated with different treatments in the present study included: total length (TL), standard length (SL), total body depth (TBD), caudal peduncle length (CPL), dorsal fin length (DFL), anal fin length (AFL), caudal fin length (CFL), pre dorsal distance (PDD), pre anal distance (PAD), pre ventral distance (PVD), head length (HL), head width (HW), eye dia (ED), maxillary barbell length (MBL), inter orbital length (IOL). On the other hand, yolk volume was determined according to the formula developed by Bagarinao (1986) for a prolate spheroid, $\mathrm{YV}=\pi / 6 \mathrm{LH}^{2}$, where $\mathrm{L}$ denotes the length of yolk sac (YL) and $\mathrm{H}$ denotes height of yolk sac (YH). Phenotypic data assessed during this study were analyzed using the standard protocols of biometric characterization frequently practiced in the morphological characterization studies of the African catfish (Turan et al., 2005). The photographic measurements of larvae were done using Leica stereo microscope model EZ4 integrated with 5 Megapixel HD camera (Switzerland). Image analysis software, Leica LAS EZ (Leica Application Suite, Version 20.0) was used for phenotypic traits measurement. Prior to preserving in Davidson fixation, larvae $(\mathrm{N}=27)$ were randomly weighed (body weight, BW) using a digital balance (Sartorius CPA10035) at the precision level of $0.000 \mathrm{~g}$. Final weight, final total length, specific growth rate (SGR), and survival rate were calculated in accordance with the following equations:

Final weight $(\mathrm{g})=$ Mean final weight - mean initial weight;

Total length gain $(\mathrm{cm})=$ Mean final length - mean initial length;

Specific growth rate $=\{(\mathrm{Ln}$ final weight $-\mathrm{Ln}$ initial weight $) /$ culture period $\} \times 100$;

Survival rates $=($ Number of live fish/total number stocked fish) $\times 100$

\section{Statistical analyses}

All analyses were done using ' $\mathrm{R}$ ' version 3.6.1 ( $\mathrm{R}$ Development Core Team, 2019). The descriptive statistics (means, SD, SEs, etc.) were evaluated using the 'psych' package. The Shapiro-Wilk test of normality and the Levene's tests for homogeneity of variance were checked with the 'onewaytests' package (Dag et al., 2018).

The generalized linear model (GLM) with 'quasipoisson' family option was applied using the 'pscl' package (Jackman, 2017) for the 'percentage data' (survival rate and body-color percentage) which did not comply with the assumptions of any parametric model. The 'quasi-poisson' regression is not only flexible with data assumptions but also allows for over-dispersion in the dependent variable (Mangiafico, 2016). The subsequent Tukey post-hoc test was done using the 'emmeans' package (Lenth, 2019).
In growth performance analysis, the Kruskal-Wallis test $(\mathrm{K}-\mathrm{W})$ was used as an alternative to a non-parametric one-way ANOVAmodel when the variable was not normally distributed even by any transformation, but homogeneous. The one-way ANOVA with Welch's correction or Welch test (WT) was applied using the 'onewaytests' package (Dag et al., 2018) for the variable which was not normally distributed and also not homogenized. The subsequent post-hoc test was done to find out where the variation among treatments lied. Since SGR is a percentage data, the GLM was used to analyze it.

The Principal Component Analysis (PCA) was applied to reduce the number of measured morphological traits to a few composite measures to explore the variation among treatments according to the selected morphological characteristics. The PCAs were performed using the 'FactoMineR' package (Sébastien et al., 2008). The eigenvalues of first (PC1) and second components (PC2) of PCAs were 11.81 and 0.83 which explained $78.7 \%$ and $5.5 \%$ of the total variability, respectively. Therefore, only these two PCs were used in this study.

The linear discriminant function analysis (DFA) was performed using the 'MASS' package (Venables and Ripley, 2002) to find out the differences among individuals of four treatments based on their measured morphological traits. The first linear discriminant captured 0.87 (LD1), while second one (LD2) contributed 0.092 of the total proportion of trace. Therefore, only these two linear discriminants were selected in this study. The calculated model accuracy was 0.80 which is high enough to accept it. Finally, all figures were prepared using the 'ggplot2' package (Wickham, 2016).

To explore the reason for significant variation among treatments, the non-parametric multivariate analysis of variance (MANOVA) was done using 'rank MANOVA' package (Friedrich et al., 2019) because all the morphological traits did not comply with the assumptions of parametric MANOVA. The subsequent pair-wise comparisons were checked with Tukey test using the 'multcomp' package (Hothorn et al., 2008).

\section{RESULTS}

\section{Survival rate}

The analysis revealed that treatment had a significant effect on the survival rate of the experimental fish (GLM: $\chi^{2}=33.62$ and $\mathrm{P}<0.001$ ). The subsequent post-hoc test showed that fish reared in $24 \mathrm{~L}$ had a significantly lower survival rate than those kept in 24D ( $\mathrm{z}=5.59$ and $\mathrm{P}<0.001)$ and with 12DL_PVC $(\mathrm{z}=4.09, \mathrm{P}<0.001$ and Fig. 1). Although fish stocked in $24 \mathrm{D}$ showed a marginally significant higher survival rate than those kept in $12 \mathrm{DL}$ 
PVC $(\mathrm{z}=4.09$ and $\mathrm{P}=0.066)$, there was no variation among other treatments (Fig. 1).

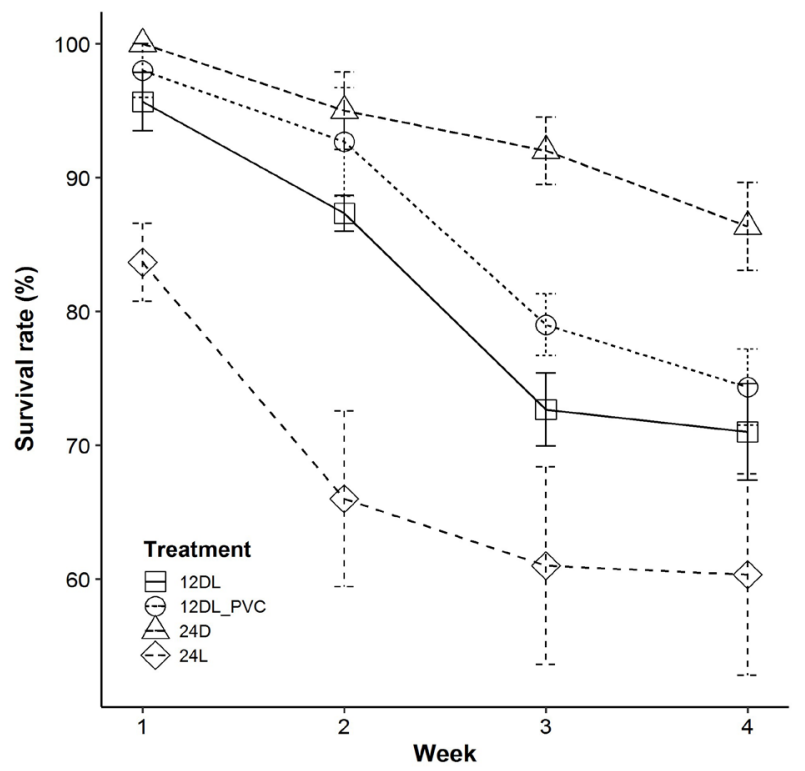

Fig. 1. Weekly percentage of survival rate $(m e a n \pm S E)$ of fish reared in different treatments during one month of the experimental period.

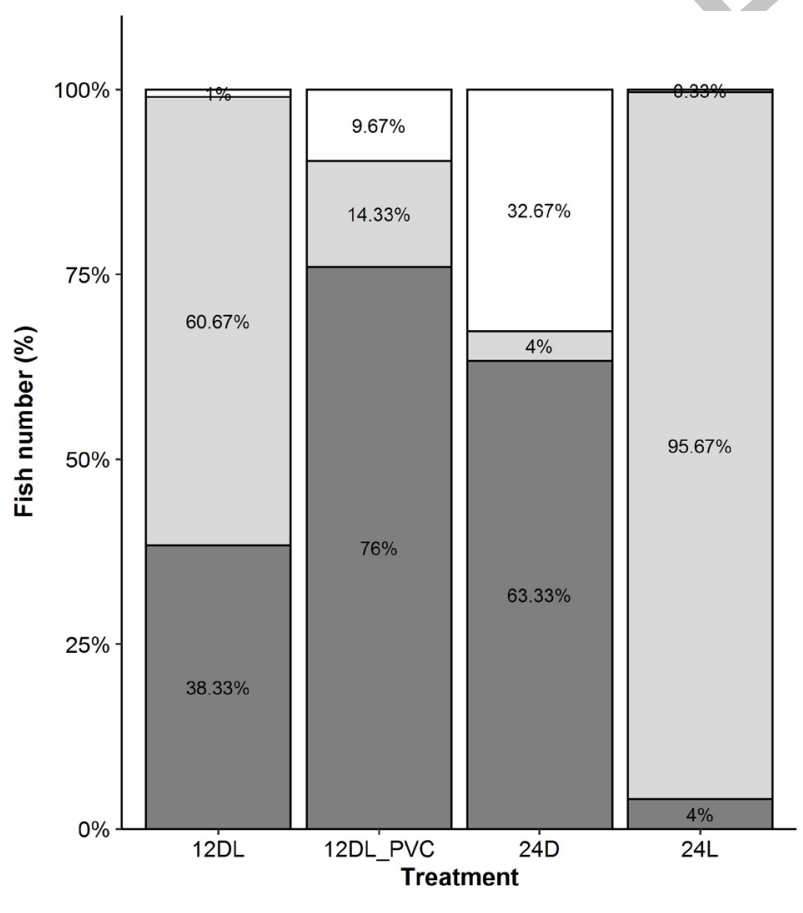

Body colour $\square$ Dark Brown $\square$ Light brown $\square$ Medium brown

Fig.2.Bodycolouration(percentage)offishrearedindifferent treatments after one month of the experimental period.

\section{Body colouration}

The observation of body colouration confirmed significant variations in light brown (GLM: $\chi^{2}=1080.2$, $\mathrm{P}<0.001$ and Fig. 2 ), medium brown (GLM: $\chi^{2}=668.51$ and $\mathrm{P}<0.001)$ and dark brown (GLM: $\chi^{2}=269.05$ and $\left.\mathrm{P}<0.001\right)$ appearances among treatments except no difference was found between $24 \mathrm{~L}(0.03 \%)$ and $12 \mathrm{DL}(1 \%)$ reared fish $(\mathrm{z}=1.14, \mathrm{P}=0.66$ and Fig. 2$)$ in case of dark brown body colouration.

\section{Growth performance}

The analysis of final growth data revealed significant variations among treatments in total length, body weight, and SGR (Table I). In all cases, fish reared in 24D showed significantly higher growth performance than other treatments, while only fish in reared 24L treatment had significantly higher SGR than those in 12DL treatment (Table I). However, no significant variation was found among other treatments in all measured growth parameters.

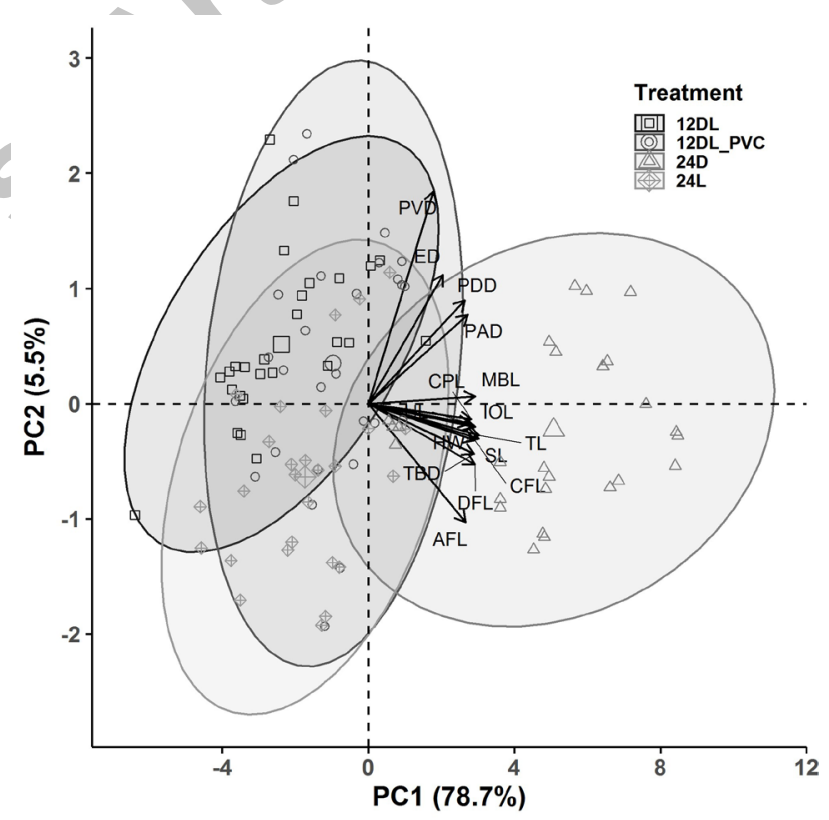

Fig. 3. Biplot of Principal Component Analysis (PCA) of 15 measured morphological traits in different treatments.

\section{Morphological traits}

The PCA analysis of 15 selected and measured morphological traits showed that the loadings of PC1 included the contributions of the most traits, while the PVD and ED were the major contributors in loadings of PC2 (Supplementary Figs. A1 and A2). The PCA variables also confirmed that these loading variables most effectively differentiated the 24D group fish from other groups (Fig. $3)$. The plotted scores of PC1 and PC1 clearly showed 
Table I. Growth performance (Mean \pm SEM) of fish reared in different treatments during one month of the experimental period. Superscript letters indicate significant differences $(P<0.05)$.

\begin{tabular}{llllllll}
\hline Traits & 24D & 24L & 12DL_PVC & 12DL & \multicolumn{2}{l}{ Stat- value P } & Model \\
\hline FBW & $0.08 \pm 0.00^{\mathrm{a}}$ & $0.05 \pm 0.00^{\mathrm{b}}$ & $0.05 \pm 0.00^{\mathrm{b}}$ & $0.05 \pm 0.00^{\mathrm{b}}$ & 113.48 & 0.001 & WT \\
FTL & $27.18 \pm 0.23^{\mathrm{a}}$ & $20.89 \pm 0.24^{\mathrm{b}}$ & $20.95 \pm 0.20^{\mathrm{b}}$ & $20.52 \pm 0.29^{\mathrm{b}}$ & 61.11 & 0.001 & $\mathrm{~K}-\mathrm{W}$ \\
SGR & $11.39 \pm 0.07^{\mathrm{a}}$ & $9.85 \pm 0.09^{\mathrm{b}}$ & $9.82 \pm 0.10^{\mathrm{bc}}$ & $9.44 \pm 0.14^{\mathrm{c}}$ & 188.78 & 0.001 & GLM \\
\hline
\end{tabular}

FBW, Final body weight (g); FTL, Final total length (mm) and SGR, Specific growth rate (\%).

that 24D treatment fish were grouped separately into the positive side of $\mathrm{PC} 1$, having very few overlapping with other groups, which mostly spread along the negative side of PC1 and overlapped each other (Fig. 3).

Consistent with the PCA analysis, the LDA outcomes confirmed distinct separation between 24D group and other treatments, which revealed two complete classes based on their measured morphological traits (Fig. 4).

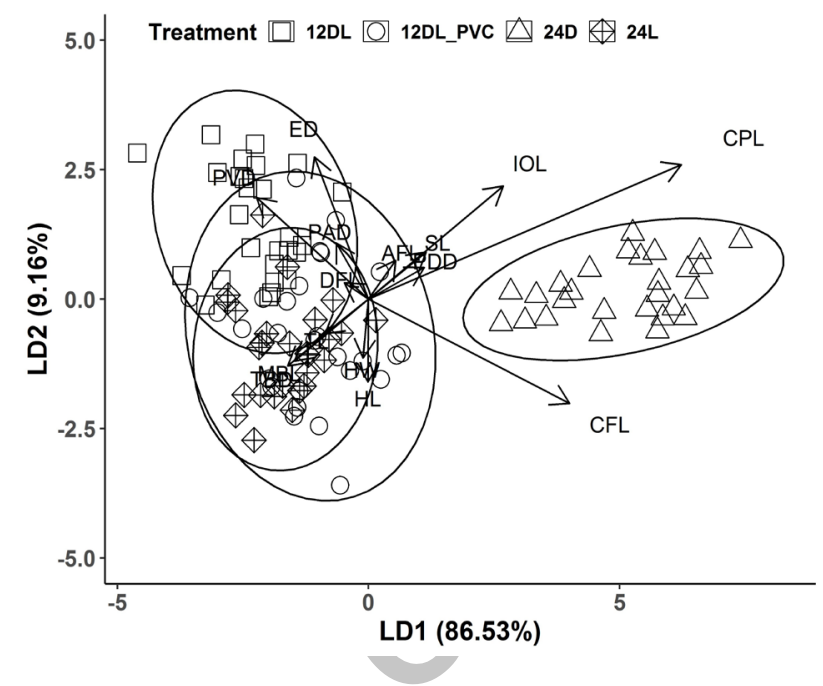

Fig. 4. Biplot of Discriminant Function Analysis (DFA) of 15 measured morphological traits in different treatments.

Finally, the non-parametric MANOVA model revealed a significant variation among the treatments (test $s t a t=286.17$ and $\mathrm{P}<0.001$ ). The subsequent pairwise comparison showed where the significant variation lay among different treatments based on the measured 15 morphological traits (Table II).

\section{DISCUSSION}

Photoperiodism (photoperiod manipulation) is routine work in aquaculture industries for gonad maturation (Lundova et al., 2019), sex alternation (Brown et al., 2014), and somatic growth (Mustapha et al., 2014; Lundova et al., 2019) in several commercially important fish species. The present study demonstrated that survival, growth, and body colouration of $C$. gariepinus larvae were directly influenced by the photoperiod manipulation. Prolonged exposed to dark condition resulted in better performance than that of prolonged light and natural conditions (12DL with and without PVC). However, the performances of larvae under shelter conditions are not as significantly conspicuous as in the dark condition.

Table II. The outcomes of pair-wise comparisons of Tukey test for non-parametric MANOVA model. Superscript letters indicate significant differences $(\mathbf{P}<0.05)$. The values are shown as Mean \pm SEM.

\begin{tabular}{lllll}
\hline $\begin{array}{l}\text { Traits } \\
\text { (mm) }\end{array}$ & 24D & 24L & 12DL_PVC & 12DL \\
\hline TL & $26.62 \pm 0.40^{\mathrm{a}}$ & $20.90 \pm 0.25^{\mathrm{b}}$ & $21.05 \pm 0.23^{\mathrm{b}}$ & $19.92 \pm 0.26^{\mathrm{d}}$ \\
SL & $22.78 \pm 0.36^{\mathrm{a}}$ & $17.79 \pm 0.21^{\mathrm{b}}$ & $17.78 \pm 0.20^{\mathrm{b}}$ & $16.92 \pm 0.21^{\mathrm{d}}$ \\
TBD & $2.26 \pm 0.07^{\mathrm{a}}$ & $1.61 \pm 0.02^{\mathrm{b}}$ & $1.66 \pm 0.02^{\mathrm{b}}$ & $1.51 \pm 0.02^{\mathrm{d}}$ \\
CPL & $1.33 \pm 0.04^{\mathrm{a}}$ & $0.70 \pm 0.01^{\mathrm{b}}$ & $0.80 \pm 0.01^{\mathrm{c}}$ & $0.73 \pm 0.02^{\mathrm{b}}$ \\
DFL & $11.3 \pm 0.11^{\mathrm{a}}$ & $9.77 \pm 0.12^{\mathrm{b}}$ & $9.57 \pm 0.12^{\mathrm{b}}$ & $9.32 \pm 0.12^{\mathrm{d}}$ \\
AFL & $8.53 \pm 0.13^{\mathrm{a}}$ & $7.38 \pm 0.09^{\mathrm{b}}$ & $7.19 \pm 0.09^{\mathrm{b}}$ & $6.97 \pm 0.09^{\mathrm{d}}$ \\
CFL & $4.01 \pm 0.04^{\mathrm{a}}$ & $3.06 \pm 0.04^{\mathrm{b}}$ & $3.12 \pm 0.05^{\mathrm{b}}$ & $2.82 \pm 0.05^{\mathrm{d}}$ \\
PDD & $9.30 \pm 0.13^{\mathrm{a}}$ & $7.33 \pm 0.10^{\mathrm{b}}$ & $7.82 \pm 0.14^{\mathrm{c}}$ & $7.68 \pm 0.10^{\mathrm{c}}$ \\
PAD & $12.00 \pm 0.15^{\mathrm{a}}$ & $9.89 \pm 0.13^{\mathrm{b}}$ & $10.36 \pm 0.12^{\mathrm{c}}$ & $10.32 \pm 0.12^{\mathrm{c}}$ \\
PVD & $2.02 \pm 0.03^{\mathrm{a}}$ & $1.81 \pm 0.02^{\mathrm{b}}$ & $1.91 \pm 0.03^{\mathrm{c}}$ & $1.91 \pm 0.02^{\mathrm{c}}$ \\
HL & $8.18 \pm 0.11^{\mathrm{a}}$ & $6.74 \pm 0.09^{\mathrm{b}}$ & $7.02 \pm 0.10^{\mathrm{b}}$ & $6.06 \pm 0.13^{\mathrm{c}}$ \\
HW & $5.10 \pm 0.04^{\mathrm{a}}$ & $4.13 \pm 0.08^{\mathrm{bc}}$ & $4.26 \pm 0.07^{\mathrm{b}}$ & $3.97 \pm 0.05^{\mathrm{c}}$ \\
ED & $0.75 \pm 0.01^{\mathrm{a}}$ & $0.66 \pm 0.02^{\mathrm{bd}}$ & $0.72 \pm 0.01^{\mathrm{c}}$ & $0.67 \pm 0.02^{\mathrm{d}}$ \\
MBL & $6.45 \pm 0.18^{\mathrm{a}}$ & $4.87 \pm 0.08^{\mathrm{bc}}$ & $5.05 \pm 0.08^{\mathrm{b}}$ & $4.67 \pm 0.08^{\mathrm{c}}$ \\
IOL & $2.87 \pm 0.04^{\mathrm{a}}$ & $2.27 \pm 0.03^{\mathrm{bc}}$ & $2.32 \pm 0.02^{\mathrm{b}}$ & $2.25 \pm 0.03^{\mathrm{c}}$ \\
\hline
\end{tabular}

TL, total length; SL, standard length; TBD, total body depth; BDA, body depth at anus; CPL, caudal peduncle length; DFL, dorsal fin length; AFL, anal fin length; CFL, caudal fin length; PDD, pre dorsal distance; PAD, pre anal distance; PVD, pre ventral distance; HL, head length; HW, head width; ED, eye dia; MBL, maxillary barbell length); IOL, inter orbital length. 
The larval stages of fish are more sensitive than any of the juvenile and adult stages, as well as more susceptible to sudden changes in environmental factors (Pereira et al., 2006). C. gariepinus larvae are photophobic in nature (Hogendoorn et al., 1980) and prefer to hide in the protected habitats on the edges of water systems (Britz and Pienaar, 1992). Appelbaum and Kamler (2000) reported that the photophobic behaviour of $C$. gariepinus is initiated shortly after hatching, which supports the observation of the present study. Newly hatched larvae stocked in tanks with PVC materials showed that all larvae took shelter in PVC pipes and larvae were mostly visible while feeding. Such tendencies were continued until the second day. Behavioral studies of $C$. gariepinus by Britz and Pienaar (1992) revealed that this species is very sensitive to light and therefore, the preference of dark condition and escaping of light are the innate characteristic features of young $C$. gariepinus. Unlike various fish species, C. gariepinus are tactile and probably chemoreceptive predators rather than visual predators therefore the contribution of eyes in searching food is less significant (Hecht and Appelbaum, 1988). Thus, rearing in darkness is advantageous for the survival and growth of $C$. gariepinus larvae.

Light tolerance in fish varies with species and plays a significant role in survival (Britz and Pienaar, 1992; SilyaGarcia, 1996; Boeuf and Le Bail, 1999). It has been verified that continuous light can harm the interests and well-being of fish and cause high mortality in various species of fish at various phases in their life cycle (Huntingford et al., 2006; Stevenson, 2007). This study proved that C. gariepinus larvae, exposed to prolonged light (24L), depressed their survival greatly compared to continuous dark (24D) or normal photoperiod (12DL), or shelter conditions (12DL PVC). Like the present study, similar analysis from Orina et al. (2016) observed a decrease in the survival rate in C. gariepinus larvae submitted to $24 \mathrm{~h}$ of light than the larvae exposed to $24 \mathrm{~h}$ dark or natural photoperiod $(12 \mathrm{~h}$ dark and $12 \mathrm{~h}$ light). In another report, working with the same species, Britz and Pienaar (1992) did not detect any variations in survival rate until 13 days of rearing under continuous dark or light, with or without cover. Yet, their conclusion revealed that under dark conditions such factors like stress, aggression and cannibalism were reduced to a considerable extent. The high mortality under prolonged light could be the result of stressful conditions that ultimately promote the aggressiveness of fish. Coeval cannibalism (i.e. cannibalism among similar-aged individuals) due to aggressiveness is a common feature in larval and juvenile Atlantic cod (Folkvord, 1997). The prolonged light also caused high mortality in other catfish species, for examples, low survival rate in the European catfish (S. glanis) larvae (Kozlowski and Poczyczynski,
1999), stinging catfish (Heteropneustes fossilis) juveniles (Rahman et al., 2020) and other finfish species such as Scophthalmus maximus juveniles (Imsland et al., 1995) and Salmo salar (Sigholt et al., 1995). Interestingly, low mortality was also detected in a number of fish species reared under natural photoperiods (Kiyono and Hirano, 1981; Tuckey and Smith, 2001; Canavate et al., 2006), while different light conditions (prolonged light/dark or natural) did not show any deleterious effect on survival in tanbaqui Aride et al. (2006), marine pejerrey Sampaio et al. (2009), Tilapia Alvarez-Rosario et al. (2009). It might, therefore, be inferred that under different photoperiods, the mortality of fish species is associated with the environment in the tank, the adaptation of the species to those surroundings, life-span of the fish, and the fish species (Mustapha et al., 2014).

Body colouration pattern of fish is a characteristic aspect that has fascinated biologists for a long time. External body colour is an important phenotypic trait and often used as a tool for predator avoidance (camouflage, bartesian mimicry, and palatability signal), prey capture (camouflage, aggressive mimicry) and conspecific communication (mating and agonistic signaling, shoaling preferences) (Cheney et al., 2008; Mills and Patterson, 2009). Body colouration also contributes to market price and consumer choice (Yilmaz and Ergün, 2011; Mustapha et al., 2012). C. gariepinus larvae reared in different exposure conditions (e.g., dark, light, and shelter) exhibited various body colourations or color differences. Dark brown colouration was mostly prevalent (predominant) in 24D photoperiod, probably due to the darkened nature of the facility, whereas lighter brown body colouration was noticed in the entirely illuminated medium (24L). Intermediate colors (light and medium brown) were observed for the larvae exposed to $12 \mathrm{DL}$ photoperiod conditions. There is also an evidence of color morph variations in another catfish group, for example in which juveniles of stinging catfish were reared for four months (120 days) under dark conditions and with shelter too (Rahman et al., 2020). Melanophores, one kind of chromatophore containing melanized organelles, termed melanosomes, generate dark colours in the skin (Sugimoto, 2002). These pigments are liable for the integumentary colouration in fish, amphibians and reptiles because of having high cellular motility (Kaur and Dua, 2015). It has been also reported that integumentary colour changes have occurred through morphological as well as physiological means (light, hormonal regulation, social interaction, stress) (Sugimoto, 2002; Nilsson Sköld et al., 2013). Melatonin is produced in the pineal gland, an endogenous time-keeping system in teleosts. Melatonin production profiles have been examined to determine 
the diurnal habits of some vertebrate species, and the hormone formed by the retinal cones and pineal glands works like a natural timer regulating locomotor activity and endogenous rhythms (Boeuf and Bail, 1999). It has been observed in teleost such as $H$. abdominalis that there is a decrease in melatonin throughout the light phase and increase throughout the dark phase (Martínez-Cárdenas et al., 2008; Leclercq et al., 2010). Deep dark body colouration along with high body mass of fish species like $C$. gariepinus offers extra profits and promotes better market value.

C. gariepinus larvae exposed to continuous dark conditions resulted in a significant improvement of growth in contrast to continuous illumination. Comparison among the treatments reveals that catfish growth improved, in order, from 24D, 12DL_PVC, 24L to 12DL treatments. Enhanced feed conversion efficiency, the reduction and absence of stress and aggressiveness, and suppression of locomotory activities in the dark may considerably increase the length, weight and other phenotypic traits (TL, SL, TBD, BDA, CPL, DFL, AFL, CFL, PDD, PAD, PVD, HL, HW, ED, MBL, IOL, YV, YL, and YH) of this larvae. Such activities allowed further energy that could be utilized on these metabolic actions to be transformed into physical development (Britz and Piennar, 1992; Appelbaum and Kamler, 2000; Almazan-Rueda et al., 2005). Such negative photosensitive behavior is also evident in other catfish species (e.g. Heterobranchus longifilis: Kerdchuen and Legendre, 1991; Silurus glanis: Kozlowski and Poczyczynski, 1999; Mystus nemurus: Rahmah et al., 2014; C. batrachus: Paramanik et al., 2014; Lophiosilurus alexandri: Kitagawa et al., 2015; Hatcheria macraei: Barriga et al., 2016; Heteropneustes fossilis: Rahman et al., 2020). Less movement, due to negative photosensitive behavior, means more energy for somatic growth and may contribute to the growth improvement. The present study also observed that under complete dark conditions, the high specific growth rate was a consequence of the full feeding and the utilization of the feed, all the more so considering the fact that these fish are nighttime feeders and photosensitive. It is predicted that the eye is not the major limiting factor for searching food; at least for Clarias gariepinus species other organ like barbels might have influence on finding food (Hecht and Appelbaum, 1988). Our results corroborate the outcomes of other fish species published elsewhere (Wilkens et al., 1997 for paddlefish, Billard and Lecointre, 2001; Ali Bani, 2009 for sturgeon). Billard and Lecointre (2001) noticed that eyes of sturgeon are comparatively very small in respect to body, and therefore, it is predicted that the eye gives no contribution to capturing food. However, the possession of highly specialized organs such as the rostrum, ampulla of lorenzini and barbels somehow make them light-independent for feeding.

Studies related to various fish species showed an extensive correlation between photoperiod (negative photosensitive) and larval development: an expansion in day-length improves the development rates for black porgy (Kiyono and Hirano, 1981), rabbit fish (Duray and Kohno, 1988), gilt-head sea bream (Chatain and OunaisGuschemann, 1991), greenback flounder (Hart et al., 1996), Atlantic salmon (Oppedal et al., 1997), snapper (Fielder et al., 2002), Sparus aurata (Ginés et al., 2004), Atlantic cod (Taranger et al., 2006), Melanogrammus aeglefinus (Davie et al., 2007), Oplegnathus fasciatus (Biswas et al., 2008), and Pagrus major (Biswas et al., 2010). Working with Nile Tilapia, Elsbaay (2013) and Biswas et al. (2002) reported that long-day photoperiods improved body weight greatly in contrast to long-night photoperiods or natural light regime. Research performed by Biswas et al. (2006) illustrated that under long and consistent photoperiods, higher development rates are confirmed because of higher food intake and food transformation ability since visual feeder fish requiring light (Cox and Pankhurst, 2000). The reduction of metabolic rate by Nile tilapia during prolonged light periods also improves the somatic growth (Elsbaay, 2013) and this statement is also supported by Biswas et al. (2002) and Biswas and Takeuchi (2002). Larvae of Clarias gariepinus exposed to light for long periods of time caused a significant reduction of growth and survival because of increased locomotory activities (for searching shelter instead of capturing food), caused them stress and aggression and thus improve cannibalistic behavior among the fish population in the tank. Many studies revealed that fish spend more energy to find shelter, which reduces feed intake during prolonged light exposure (Verreth and Van Tongeren, 1989; Britz and Pienaar, 1992; Appelbaum and Geer, 1998; Appelbaum and Kamler, 2000; AlmazánRueda et al., 2005). In European catfish (S. glanis), Kozlowski and Poczyczynski (1999) discovered that light caused a hostile attitude and more gathering of this species at the base, close to the walls and in tank corners, which eventually raised cannibalism and diminished overall growth. Yet, the manipulation of photoperiod had no impact upon the entire length and body weight of Verasper moseri (Amano et al., 2004) and Oreochromis niloticus (Campos-Mendoza et al., 2004), and female lambari (Navarro et al., 2014).

Catfish are nocturnal in nature and prefer shelter to grow, develop and reproduce (Britz and Pienaar, 1992; Rahmah et al., 2014; Barriga et al., 2016). The present study revealed that newly hatched larvae took shelter in tanks that were equipped with PVC pipes while larvae formed clusters and accumulated at the corner of tanks 
where PVC pipes were absent. Installation of PVC pipes in tanks has shown better growth in case of Patagonian catfish (Barriga et al., 2016), and Asian walking catfish (Sahiduzzaman et al., 2018). This study did not notice any significant effect on growth in the case of shelter provided tanks. In a recent study with stinging catfish, Rahman et al. (2020) demonstrated that PVC itself in dark has no influence on growth, which corroborates the findings of the present study. Although we did not obtain better growth in the presence of PVC as shelter materials, the survival rate was higher compared to non-PVC tanks and this could be attributed to the fact that PVC provides shelter that increases the resting time and reduces stress and thereby influences survival (Hecht and Appelbaum, 1988; Rahman et al., 2020).

\section{CONCLUSION}

Together with early studies, the study showed again that colouration pattern, growth performances and survival of $C$. gariepinus larvae were directly influenced by photoperiod, while no significant influence was revealed by the shelter effect. Rearing under the prolonged dark condition resulted in several folds of phenotypic growth and increased survival. The highest survival was recorded in 24D followed by 12DL_PVC, 24L, and 12DL, respectively. The complete dark brown body color (resembled as typical fish color) was observed in 24D condition and this shiny color may gain in consumer preference for regular consumption of this species. Shelter itself, which is not influencing but could be promising for better larval survival in dark conditions, needs to be studied further. Additional research is also required on the effect of other larval stages and environmental stimuli on growth performances of this and other commercially important fish species. Since the larval stage is more sensitive, rearing in dark conditions could be economical in terms of better aquaculture production by obtaining enhanced survival and growth.

\section{ACKNOWLEDGEMENTS}

This study was supported by the internal funds of the Fish Resources Research Center, King Faisal University, KSA. We are indebted to all the staff of Fish Resources Research Center for their continuous support during the study. The senior author (ASA) is acknowledged by the Deanship of Scientific Research at the King Faisal University for a grant under Nasher track (186293).

\section{Ethics statement}

All animal procedures were approved by the
Research Ethics Committee (REC) of the King Faisal University (KSA) and complied with the Guidelines on Ethical Treatment of Experimental Animals (KFUREC/2020-02-01) set by the Ministry of Science and Technology, KSA.

\section{Supplementary material}

There is supplementary material associated with this article. Access the material online at: http://dx.doi. org/10.17582/journal.pjz/2019.51..........

\section{Statement of conflict of interest}

The authors have declared no conflicts of interest.

\section{REFERENCES}

Adebayo, O.T. and Popoola, O.M., 2008. Comparative evaluation of efficacy and cost of synthetic and non-synthetic hormones for artificial breeding of African catfish (Clarias gariepinus Burchell, 1822). J. Fish. aquat. Sci., 3: 66-71. https://doi. org/10.3923/jfas.2008.66.71

Ali Bani, B., Mehdi, T., Bahram, F. and Ashkan, B., 2009. Effects of different photoperiods on growth, stress and haematological parameters in juvenile great sturgeon Huso huso. Aquacul. Res., 40: 1899-1907. https://doi.org/10.1111/j.1365-2109.2009.02321.x

Ali, M.S., Shofiquzzoha, A.F.M. and Ahmed, S.U., 1999. Effect of submerged aquatic vegetation on growth and survival of Penaeus monodon (Fab.). Bangladesh J. Fish. Res., 3: 145-149.

Almazán-Rueda, P., Schrama, J.W. and Verreth, J.A.J., 2004. Behavioral responses under different feeding methods and light regimes of the African catfish (Clarias gariepinus) juveniles. Aquaculture, 231: $\quad 347-359$. https://doi.org/10.1016/j. aquaculture.2003.11.016

Almazán-Rueda, P., Van Helmond, A.T., Verreth, J.A. and Schrama, J.W., 2005. Photoperiod affects growth, behaviour and stress variables in Clarias gariepinus. J. Fish Biol., 67: 1029-1039. https:// doi.org/10.1111/j.0022-1112.2005.00806.x

Alvarez-Rosario, J., Feliz-Carrasco, L., MontoyaOspina, R. and Velasco, M., 2009. Tilapia fry perform similarly under varied photoperiods. Global Aquacul. Advocate, pp. 70-72.

Amano, M., Yamanome, T., Yamada, H., Okuzawa, K. and Yamamori, K., 2004. Effects of photoperiod on gonadotropin-releasing hormone levels in the brain and pituitary of underyearling male barfin flounder. Fish. Sci., 70: 812-818. https://doi.org/10.1111/ j.1444-2906.2004.00874.x 
Appelbaum, S. and Kamler, E., 2000. Survival, growth, metabolism and behaviour of Clarias gariepinus (Burchell 1822) early stages under different light conditions. Aquacult. Eng., 22: 269-287. https:// doi.org/10.1016/S0144-8609(00)00054-6

Appelbaum, S. and McGeer, J.C., 1998. Effect of diet and light regime on growth and survival of African catfish (Clarias gariepinus) larvae and early juveniles. Aquacult. Nutr., 4: 157-164. https://doi. org/10.1046/j.1365-2095.1998.00064.x

Aride, P.H., Roubach, R.R., Nozawa, S.R. and Val, A.L., 2006. Tambaqui growth and survival when exposed to different photoperiods. Acta Amazon., 36: $381-384$. https://doi.org/10.1590/S004459672006000300015

Bagarinao, T., 1986. Yolk resorption, onset of feeding and survival potential of larvae of three tropical marine fish species reared in the hatchery. Mar. Biol., 91: 449-459. https://doi.org/10.1007/ BF00392595

Barlow, C.G., Pearce, M.G., Rodgers, L.J. and Clayton, P., 1995. Effects of photoperiod on growth, survival, and feeding periodicity of larval and juvenile barramundi, Lates calcarifer (Bloch). Aquaculture, 138: 159-168. https://doi.org/10.1016/00448486(95)01073-4

Barriga, J.P., Espinós, N.A., Torres, W.D.C. and Battini, M.Á., 2016. Diel locomotor activity and shelter use in the Patagonian catfish Hatcheria macraei under experimental conditions. J. Ethol., 34: 53-58. https://doi.org/10.1007/s10164-015-0445-5

Barton, B. and Iwama, G.K., 1991. Physiological changes in fish from stress in aquaculture with emphasis on the response and effects of corticosteroids. Annu. Rev. Fish Dis., 1: 3-26. https://doi.org/10.1016/0959-8030(91)90019-G

Beck, M.W., Heck, K.L.Jr., Able, K.W., Childers, D.L., Eggleston, D.B., Gillanders, B.M., Halpern, B., Hays, C.G., Hoshino, K., Minello, T.J., Orth, R.J., Sheridan, P.F. and Weinstein, M.P., 2009. The identification, conservation, and management of estuarine and marine nurseries for fish and invertebrates: A better understanding of the habitats that serve as nurseries for marine species and the factors that create site-specific variability in nursery quality will improve conservation and management of these areas. BioScience, 51: 633-641. https://doi. org/10.1641/0006-3568(2001)051[0633:TICAMO 12.0.CO;2

Benaka, L.R., 1999. Fish habitat: Essential fish habitat and rehabilitation. American Fisheries Society, Bethesda, Maryland. pp. 459.
Billard, R. and Lecointre, G., 2001. Biology and conservation of sturgeon and paddle fish. Rev. Fish Biol. Fisher., 10: 355-392. https://doi. org/10.1023/A:1012231526151

Biswas, A.K. and Takeuchi, T., 2002. Effects of different photoperiod cycles on metabolic rate and energy loss of both fed and unfed adult tilapia Oreochromis niloticus: part II. Fish. Sci., 68: 543-553. https:// doi.org/10.1046/j.1444-2906.2002.00460.x

Biswas, A.K., Endo, M. and Takeuchi, T., 2002. Effects of different photoperiod cycles on metabolic rate and energy loss of both fed and unfed young tilapia Orochromis niloticus: part I. Fish. Sci., 68: 465-477. https://doi.org/10.1046/j.1444-2906.2002.00450.x

Biswas, A.K. and Takeuchi, T., 2003. Effects of photoperiod and feeding interval on food intake and growth rate of Nile tilapia Oreochromis niloticus. Fish. Sci., 69: 1010-1016. https://doi.org/10.1046/ j.1444-2906.2003.00720.x

Biswas, A.K., Morita, T., Yoshizaki, G., Maita, M. and Takeuchi, T., 2005. Control of reproduction in Nile tilapia Oreochromis niloticus (L.) by photoperiod manipulation. Aquaculture, 243: 229-239. https:// doi.org/10.1016/j.aquaculture.2004.10.008

Biswas, A.K., Seoka, M., Tanaka, Y., Takii, K. and Kumai, H., 2006. Effect of photoperiod manipulation on the growth performance and stress response of juvenile red sea bream (Pagrus major). Aquaculture, 258: 350-356. https://doi. org/10.1016/j.aquaculture.2006.03.048

Biswas, A.K., Seoka, M., Ueno, K., Yong, A.S.K., Biswas, B.K., Kim, Y.S., Takii, K. and Kumaia, H., 2008. Growth performance and physiological responses in striped knifejaw, Oplegnathus fasciatus, held under different photoperiods. Aquaculture, 279: 42-46. https://doi.org/10.1016/j. aquaculture.2008.04.007

Biswas, A., Seoka, M., Inagaki, H. and Takii, K., 2010. Reproduction, growth and stress response in adult red sea bream, Pagrus major exposed to different photoperiod at spawning season, Aquacul. Res., 41: 519-527. https://doi.org/10.1111/j.13652109.2009.02341.x

Boerrigter, J.G.J., Bos, R. van den., Vis, H. van de., Spanings, T. and Flik, G., 2016. Effects of density, PVC-tubes and feeding time on growth, stress and aggression in in African catfish (Clarias gariepinus). Aquacul. Res., 47: 2553-2568. https:// doi.org/10.1111/are.12703

Boeuf, G. and Bail, P.Y.L., 1999. Does light have an influence on fish growth? Aquaculture, 177: 129-152. https://doi.org/10.1016/S0044- 
8486(99)00074-5

Boeuf, G. and Falco'n, J., 2001. Photoperiod and growth in fish. Vie Milieu, 51: 247-266.

Bovendeur, J., Eding, E.H. and Henken, A.M., 1987. Design and performance of a water recirculation system for high density culture of African Catfish, Clarias gariepinus (Burchel 1822). Aquaculture, 63: 329-353. https://doi.org/10.1016/00448486(87)90083-4

Britz, P.J. and Pienaar, A.G., 1992. Laboratory experiments on the effects of light and cover on the behaviour and growth of African catfish, Clarias gariepinus (Pisces: Clariidae). J. Zool., 227: 4362. https://doi.org/10.1111/j.1469-7998.1992. tb04343.x

Bromage, N., Porter, M. and Randall, C., 2001. Environmental regulation of maturation in farmed finfish with special reference to the role of photoperiod and melatonin. Aquaculture, 197: 63-99. https://doi.org/10.1016/B978-0-444-50913$0.50008-4$

Brown, E., Baumann, H. and Conover, D., 2014. Temperature and photoperiod effects on sex determination in a fish. J. exp. mar. Biol. Ecol., 461: 39-43. https://doi.org/10.1016/j.jembe.2014.07.009

Campos-Mendoza, A., Mcandrew, B., Coward, K. and Bromage, N.R., 2004. Reproductive response of Nile tilapia (Oreochromis niloticus) to photoperiodic manipulation. Aquaculture, 231: 299-314. https:// doi.org/10.1016/j.aquaculture.2003.10.023

Canavate, J.P., Zerolo, R. and Fernandez-Diaz, C., 2006. Feeding and development of Senegal sole (Solea senegalensis) larvae reared in different photoperiods. Aquaculture, 258: 368-377. https:// doi.org/10.1016/j.aquaculture.2006.04.009

Chatain, B. and Ounais-Guschemann, N., 1991. The relationships between light and larvae of Sparus Aurata. In:, Larvi 91-Fish and crustacean larviculture Symposium (eds. P. Lavens, P. Sorgeloos, E. Jaspers and F. Ollevie). European Aquaculture Society, Special Publication, 15: 310313.

Cheney, K.L., Grutter, A. and Marshall, N.J., 2008. Facultative mimicry: Cues for colour change and colour accuracy in a coral reef fish. Proc. R. Soc. Lond. B, 275: 117-122. https://doi.org/10.1098/ rspb. 2007.0966

Chua, T.E. and Teng, S.K., 1979. Relative growth and production of the estuary grouper Epinephelus salmoides under different stocking densities in floating net-cages. Mar. Biol., 54: 363-372. https:// doi.org/10.1007/BF00395442
Cox, E.S. and Pankhurst, P.M., 2000. Feeding behaviour of greenback flounder larvae, Rhombosolea tapirina (Günther) with differing exposure histories to live prey. Aquaculture, 183: 285-297. https://doi. org/10.1016/S0044-8486(99)00302-6

Dag, O., Dolgun, A. and Konar, N.M., 2018. Onewaytests: An R package for one-way tests in independent groups designs. The R. J., 10: 175199. https://doi.org/10.32614/RJ-2018-022

Davie, A., Mazorra de Quero, C., Bromage, N., Treasurer, J. and Migaud, H., 2007. Inhibition of sexual maturation in tank reared haddock (Melanogrammus aeglefinus) through the use of constant light photoperiods. Aquaculture, 270: $379-389$. https://doi.org/10.1016/j. aquaculture.2007.04.052

De Graaf, G. and Janssen, H., 1996. Artificial reproduction and pond rearing of the African catfish Clarias gariepinus in sub-Saharan Africa. FAO Fisheries Technical Paper, Food and Agriculture Organization of the United Nations, Rome, Italy.

Denson, M.R. and Smith, T.I.J., 1997. Diet and light intensity effects on survival, growth and pigmentation of southern flounder Paralichthys lethostigema. J. World Aquacult. Soc., 28: 366373. https://doi.org/10.1111/j.1749-7345.1997. tb00283.x

Duray, M.N. and Kohno, H., 1988. Effect of continuous lighting on growth and survival of first feeding larval rabbitfish, Siganus guttatus. Aquaculture, 72: 7379. https://doi.org/10.1016/0044-8486(88)90147-0

Duston, J. and Saunders, R.L., 1990. The entrainment role of photoperiod on hypo osmoregulatory and growth-related aspects of smolting in Atlantic salmon (Salmo salar). Can. J. Zool., 68: 707-715. https://doi.org/10.1139/z90-103

Elsbaay, A.M., 2013. Effects of photoperiod and different artificial light colors on Nile tilapia growth Rate. IOSR J. Agric. Vet. Sci., 3: 5-12. https://doi. org/10.9790/2380-0330512

Endal, H.P., Taranger, G.L., Stefansson, S.O. and Hansen, T., 2000. Effects of continuous additional light on growth and sexual maturity in Atlantic Salmon, Salmo salar, reared in sea cages. Aquaculture, 191: 337-349. https://doi.org/10.1016/S00448486(00)00444-0

Fielder, D.S., Bardsley, W.J., Allan, G.L. and Pankhurst, P.M., 2002. Effect of photoperiod on growth and survival of snapper Pagrus auratus larvae. Aquaculture, 211: 135-150. https://doi.org/10.1016/ S0044-8486(02)00006-6

Folkvord, A., 1997. Ontogeny of cannibalism in larval 
and juvenile fishes with special emphasis on Atlantic cod. In: Early life history and recruitment in fish populations (eds. R.C. Chambers and E.A. Trippel). Chapman and Hall, London, pp. 251-278. https://doi.org/10.1007/978-94-009-1439-1_9

Friedrich, S., Dobler, D. and Pauly, M., 2019. Rankbased tests for multivariate data in nonparametric factorial designs. $\mathrm{R}$ package version 0.0.6. URL: http://github.com/smn74/rankMANOVA.

Ginés, R., Afonso, J.M., Argüello, A., Zamorano, M.J. and López, J.L., 2004. The effects of long-day photoperiod on growth, body composition and skin colour in immature gilthead sea bream (Sparus aurata L.). Aquacul. Res., 35: 1207-1212. https:// doi:10.1111/j.1365-2109.2004.01126.x

Granqvist, M. and Mattila, J., 2004. The effects of turbidity and light intensity on the consumption of mysids by juvenile perch (Perca fluviatilis L.). J. Hydrobiol., 514: 93-101. https://doi. org/10.1007/978-94-017-0920-0_9

Hallaråker, H., Folkvord, A. and Stefansson, S.O., 1995. Growth of juvenile halibut (Hippoglossus hippoglossus) related to temperature, day length and feeding regime. Netherlands J. Sea Res., 34: 139-147. https://doi.org/10.1016/00777579(95)90022-5

Hart, P.R., Hutchinson, W.G. and Purser. G.J., 1996. Effects of photoperiod, temperature and salinity on hatchery-reared larvae of the greenback flounder (Rhombosolea tapirine Gunther, 1862). Aquaculture, 144: 303-311. https://doi. org/10.1016/0044-8486(96)01305-1

Harvey, E., Butler, J.J., Mclean, D. and Shand, J., 2012. Contrasting habitat use of diurnal and nocturnal fish assemblages in temperate Western Australia. J. exp. mar. Biol. Ecol., 426: 78-86. https://doi. org/10.1016/j.jembe.2012.05.019

Hecht, T., 2013. A review of on-farm feed management practices for North African catfish (Clarias gariepinus) in sub-Saharan Africa. In: On-farm feeding and feed management in aquaculture (eds. M.R. Hasan and M.B. New). FAO Fisheries and Aquaculture technical Paper No. 583, pp. 463-479.

Hecht, T. and Appelbaum, S., 1988. Observations on intraspecific aggression and coeval sibling cannibalisminjuvenile Clariasgariepinus(Clariidae Pisces) under controlled conditions. J. Zool., 214: 21-44. https://doi.org/10.1111/j.1469-7998.1988. tb04984.x

Hogendoorn, H., Hardeman, G.J., Vismans, M.M. and Viveen, W.J.A.R., 1980. Controlled propagation of the labyrinthic catfish, Clarias lazera (C. and
V.) for experimental purposes. In: Proceedings of the $7^{\text {th }}$ ICLAS Symposium, Utrecht, 1979. Gustav Fisher, Stuttgart, pp. 363-371.

Holbrook, S. and Schmitt, R., 2002. Competition for shelter space causes density dependent predation mortality in damselfishes. Ecology, 83: 2855-2868. https://doi.org/10.1890/00129658(2002)083[2855:CFSSCD]2.0.CO;2

Hossain, M., Beveridge, M. and Haylor, G., 1998. The effects of density, light and shelter on the growth and survival of African catfish (Clarias gariepinus Burchell, 1822) fingerlings. Aquaculture, 160: 251-258. https://doi.org/10.1016/S00448486(97)00250-0

Hossain, M., Batty, R.S., Haylor, G. and Beveridge, M., 1999. Diel rhythms of feeding activity in African catfish, Clarias gariepinus (Burchell, 1822). Aquacult. Res., 30: 901-905. https://doi. org/10.1046/j.1365-2109.1999.00421.x

Hothorn T., Bretz F. and Westfall, P., 2008. Simultaneous inference in general parametric models. Biomed. J., 50: 346-363. https://doi.org/10.1002/ bimj. 200810425

Huntingford, F.A., Adams, C.E., Braithwaite, V.A., Kadri, S., Pottinger, T.G., Sandoe, P. and Turnbull, J. F., 2006. Current issues in fish welfare. J. Fish Biol., 68: 332-372. https://doi.org/10.1111/j.00221112.2006.001046.x

Iigo, M., Kezuka, H., Adia, K. and Hanyu, I., 1991. Circadian rhythms of melatonin secretion from superfused goldfish (Carassius auratus) pineal glands in vitro. Gen. Comp. Endocr., 83: 152-158. https://doi.org/10.1016/0016-6480(91)90115-M

Imsland, A., Folkvord, A.F. and Stefansson, S.O., 1995. Growth, oxygen consumption and activity of juvenile turbot Scophthalmus maximus L. reared under different temperatures and photoperiods. Netherlands J. Sea Res., 34: 149-159. https://doi. org/10.1016/0077-7579(95)90023-3

Ishida, C.K., Arnon, S., Peterson, C.G., Kelly, J.J. and Gray, K.A., 2008. Influence of algal community structure on denitrification rates in periphyton cultivated on artificial substrata. Microb. Ecol., 56: 140-152. https://doi.org/10.1007/s00248-0079332-0

Jackman, S., 2017. Pscl: Classes and methods for $R$ developed in the Political Science Computational Laboratory. United States Studies Centre, University of Sydney. Sydney, New South Wales, Australia. R package version 1.5.2. URL: https:// github.com/atahk/pscl/

Johansen, J., Bellwood, D. and Fulton, C., 2008. 
Coral reef fishes exploit flow refuges in highflow habitats. Mar. Ecol-Prog. Ser., 360: 219-226. https://doi.org/10.3354/meps07482

Johnson, D.L. and Stein, R.A., 1979. Response of fish to habitat structure in standing water. North Central Division American Fisheries Society: Bethesda, Maryland.

Kaur, R. and Dua, A., 2015. Colour changes in Labeo rohita (Ham.) due to pigment translocation in melanophores, on exposure to municipal wastewater of Tung Dhab drain, Amritsar, India. Environ. Toxicol. Pharmacol., 39: 747-757. https:// doi.org/10.1016/j.etap.2015.01.007

Kerdchuen N. and Legendre, M., 1991. Influence de la fréquence et de la période de nourrissage sur la croissance et l'efficacité alimentaire d'un silnre africain, Heterobranchus Iongijlis (Teleostei, Clariiddae). Aquat. Living Resour., 4: 341-348. https://doi.org/10.1051/alr:1991025

Kitagawa, A.T., Costa, L.S., Paulino, R.R., Luz, R.K., Rosa, P.V. and Silva, R.F., 2015. Feeding behavior and the effect of photoperiod on the performance and hematological parameters of the pacamã catfish (Lophiosilurus alexandri). Appl. Anim. Behav. Sci., 171: 211-218. https://doi.org/10.1016/j. applanim.2015.08.025

Kiyono, M. and Hirano, R., 1981. Effects of light on the feeding and growth of black porgy, Mylio macrocephalus (Basilewsky) postlarvae and juveniles. Rap. Procès-Verbaux Réunions Conseil Int. Explor. Mer., 178: 334-336.

Kozlowski, J. and Poczyczynski, P., 1999. The effect of light and stocking density on the results of rearing of European catfish (Silurus glanis L.) larvae. Arch. Rybact. Pol., 7: 297-306.

Leclercq, E., Taylor, J.F. and Migaud, H., 2010. Morphological skin colour changes in teleosts. Fish Fish., 11: 159-193. https://doi.org/10.1111/j.14672979.2009.00346.x

Lenth, R., 2019. Emmeans: Estimated marginal means, aka least-squares means. $\mathrm{R}$ package version 1.4.2. URL: https:/CRAN.R-project.org/ package $=$ emmeans.

Lundova, K., Matousek, J., Prokesova, M., Vanina, T., Sebesta, R., Urban, J. and Stejskal, V., 2019. The effects of a prolonged photoperiod and light source on growth, sexual maturation, fin condition, and vulnerability to fungal disease in brook trout Salvelinus fontinalis. Aquacult. Res., 50: 256-267. https://doi.org/10.1111/are.13891

MacPhail, R.C., Brooks, J., Hunter, D.L., Padnos, B., Irons, T.D. and Padilla, S., 2009. Locomotion in larval zebrafish: influence of time of day, lighting and ethanol. Neuro Toxicol., 30: 52-58. https://doi. org/10.1016/j.neuro.2008.09.011

Mangiafico, S., 2016. Summary and analysis of extension program evaluation in $R$, version 1.15.0. Retrieved from: http://rcompanion.org/handbook/J_01.html.

Martínez-Cárdenas, L., Porter, M. and Purser, G.J., 2008. Light-dark variations in plasma melatonin concentrations in pot-bellied seahorse Hippocampus abdominalis Lesson, 1827. J. Fish Biol., 72: 1799-1803. https://doi.org/10.1111/ j.1095-8649.2008.01833.x

Mathiesen, A.M., 2012. The state of the world fisheries and aquaculture 2012. Food and Agriculture Organization, Rome, Italy.

Mendonça, P.P., Ferreira1, R.A., Vidal Junior M.V., Andrade, D.R., Santos, M.V.B., Ferreira, A.V. and Rezende, F.P., 2009. Influência do fotoperíodo no desenvolvimento de juvenis de tambaqui (Colossoma macropomum). Arch. Zootec., 58: 323-331. https://doi.org/10.4321/S000405922009000300001

Mills, M.G. and Patterson, L.B., 2009. Not just black and white: Pigment pattern development and evolution in vertebrates. Sem. Cell Develop. Biol., 20: 72-81. https://doi.org/10.1016/j.semcdb.2008.11.012

Moore, K.L., Graham, M.A. and Barr, M.L., 1953. The detection of chromosomal sex in hermaphrodites from a skin biopsy. Surg. Gynecol. Obstet., 96: 641-648. https://doi.org/10.1007/978-94-0116621-8 12

Moring, J.R. and Nicholson, P.H., 1994. Evaluation of three types of artificial habitats for fishes in a freshwater pond in Maine, USA. Bull. mar. Sci., 55: 1149-1159. https://doi.org/10.2478/v10086012-0007-1

Mustapha, M.K., Okafor, B.U., Olaoti, K.S. and Oyelakin, O.K., 2012. Effects of three different photoperiods on the growth and body coloration of juvenile African catfish, Clarias gariepinus (Burchell). Arch. Pol. Fish., 20: 55-59.

Mustapha, M.K., Oladokun, T.T., Salman, M.M., Adeniyi, I.A. and Ojo, D., 2014. Does light duration (photoperiod) have effect on the mortality and welfare of cultured Oreochromis niloticus and Clarias gariepinus? Turk. J. Zool., 38: 466-470. https://doi.org/10.3906/zoo-1309-23

Narejo, N.T., Rahmatullah, S.M. and Rashid, M.M., 2003. Effect of different shelters on growth, survival and production of freshwater mud eel, Monopterus cuchia (Hamilton) reared in concreted cisterns of BAU Mymensingh, Bangladesh. Pak. 
J. biol. Sci., 6: 1753-1757. https://doi.org/10.3923/ pjbs.2003.1753.1757

Navarro, F.K.S.P., Navarro, R.D., Murgas, L.D.S. and Felizardo, V.O., 2014. Effect of photoperiod stress assessment and locomotor activity of female lambari (Astyanax bimaculatu). Cienc. Agrotec., 38: $173-180 . \quad$ https://doi.org/10.1590/S141370542014000200008

Nilsson-Sköld, H., Aspengren, S. and Wallin, M., 2013. Rapid color change in fish and amphibians - function, regulation, and emerging applications. Pigm. Cell Melanoma R., 26: 29-38. https://doi. org/10.1111/pcmr.12040

Nybakken, J.W., 1993. Intertidal ecology. In: Marine biology: An ecological approach (ed. J.W. Nybakken). Harper Collins College Publishers, New York, pp. 219-282.

Oppedal, F., Taranger, G.L., Juell, J.E., Fosseidengen, J.E. and Hansen, T., 1997. Light intensity affects growth and sexual maturation of Atlantic salmon (Salmo salar) postsmolts in sea cages. Aquat. Living Resour., 10: 351-357. https://doi.org/10.1051/ alr:1997038

Orina, S., Rasowo, J., Oyoo-Okoth, E., Musa, S., Munguti, J. and Charo-Karisa, H., 2016. Combined effects of photoperiod and temperature on growth and survival of African catfish (Clarias gariepinus, Burchell 1822) larvae under laboratory conditions. J. appl. Aquacult., 28: 17-25. https://doi.org/10.10 80/10454438.2015.1113763

Paramanik, M., Ferosekhan, S. and Sahoo, S.K., 2014. Does the dark condition enhance growth and survival of Clarias batrachus larvae at higher stocking density?. Int. J. Fish. aquat. Stud., 2: 142144.

Pereira, C.R., Barcellos, L.J.G., Kreutz, L.C., Quevedo, R.M., Ritter, F. and Silva, L.B., 2006. Embryonic and larval development of Jundiá (Rhamdia quelen, Quoy and Gaimard, 1824, Pisces, Teleostei), a South American Catfish. Braz. J. Biol., 66: 1057-1063. https://doi.org/10.1590/S151969842006000600013

Purchase, C.F., Boyce, D.L. and Brown, J.A., 2000. Growth and survival of juvenile yellowtail flounder (Pleuronectes ferrugineus Storer) under different photoperiods. Aquac. Res., 31: 547-552. https:// doi.org/10.1046/j.1365-2109.2000.00480.x

R Development Core Team. 2019. R: A language and environment for statistical computing, version 3.6.1. R Foundation for Statistical Computing, Vienna, Austria. URL: https:/www.r- project.org/

Rahmah, S., Kato, K., Yamamoto, S., Takii, K., Murata,
O. and Senoo, S., 2014. Improved survival and growth performances with stocking density manipulation and shelter availability in bagrid catfish Mystus nemurus (Cuvier and Valenciennes 1840) larvae. Aquacul. Res., 45: 2000-2009. https:// doi.org/10.1111/are.12148

Rahman, M.M., Nur, N., Mahmud-Al-Hasan, M., Asaduzzaman, S., Rouf, M.A. and Rahman, S.M., 2020. Effects of light and artificial fish shelter (PVC pipe) on some phenotypic traits of stinging catfish (Heteropneustes fossilis Bloch, 1794). Aquacul. Res., 51: 124-134. https://doi.org/10.1111/ are. 14354

Sahiduzzaman, S., Tauhiduzzaman, and Rahman, S.M., 2018. Effects of shelter on growth and survival of Asian catfish (Clarias batrachus). Int. J. Fish. aquat. Res., 3: 60-63.

Sampaio, L.A., Freitas, S.L., Rodrigues, R.V., Okamoto, M.H. and Louzada, R.L., 2009. Effects of photoperiod on survival and growth of the marine pejerrey Odontesthes argentinensis larvae. Aquacul. Res., 40: 252-255. https://doi.org/10.1111/ j.1365-2109.2008.02080.x

Sébastien, L., Josse, J. and Husson, F., 2008. Facto Mine R: An R package for multivariate analysis. $J$. Stat. Softw. 25: 1-18.

Seebacher, F. and Alford, R.A., 2002. Shelter microhabitats determine body temperature and dehydration rates of a terrestrial amphibian (Bufo marinus). J. Herpetol., 36: 69-75. https://doi. org/10.1670/0022-1511(2002)036[0069:SMDBTA ]2.0.CO;2

Sigholt, T., Staurnes, M., Jakobsen, H.J. and Asgard, T., 1995. Effects of continuous light and short-day photoperiod on smolting, seawater survival and growth in Atlantic salmon (Salmo salar). Aquaculture, 130: 373-388. https://doi. org/10.1016/0044-8486(94)00349-S

Silva-Garcia, A.J., 1996. Growth of juvenile gilthead seabream Sparus aurata L reared under different photoperiod regimes. Isr. J. Aquacult-Bamid., 48: 84-93.

Simensen, L.M., Jonassen, T., Imsland, A.K. and Stefansson, S., 2000. Photoperiod regulation of growth of juvenile halibut (Hippoglossus hippoglossus L.) reared at different photoperiods. Aquaculture, 119: 119-128. https://doi.org/10.1016/ S0044-8486(00)00397-5

Srivastava, S., 2003. Influence of continuous light and darkness on the secretory pinealocytes of Heteropneustes fossilis. J. Biosci., 28: 613-622. https://doi.org/10.1007/BF02703337 
Stevenson, P., 2007. Closed waters: The welfare of farmed atlantic salmon, Rainbow Trout, Atlantic Cod and Atlantic Halibut. Godalming, Surrey, UK: Compassion in World Farming and World Society for the Protection of Animals.

Sugimoto, M., 2002, Morphological color changes in fish: Regulation of pigment cell density and morphology. Microsc. Res. Tech., 58: 496-503. https://doi.org/10.1002/jemt.10168

Tałanda, J., Maszczyk, P. and Babkiewicz, E., 2018. The reaction distance of a planktivorous fish (Scardinius erythrophthalmus) and the evasiveness of its prey (Daphnia pulex $\times$ pulicaria) under different artificial light spectra. Limnology, 19: 311-319. https://doi.org/10.1007/s10201-018-0548-0

Taranger, G.L., Aardal, L., Hansen, T. and Kjesbu, O.S., 2006. Continuous light delays sexual maturation and increases growth of Atlantic cod (Gadus morhua L.) in sea cages. ICES J. mar. Sci., 63: 365375. https://doi.org/10.1016/j.icesjms.2005.10.014

Teugels, G.G., 1986. A systematic revision of the African species of the genus Clarias (Pisces: Clariidae). Annl. Mus. R. Centr., 247: 1-199.

Tian, H.Y., Zhang, D.D., Xu, C., Wang, F. and Liu, W.B., 2015. Effects of light intensity on growth, immune responses, antioxidant capability and disease resistance of juvenile blunt snout bream Megalobrama amblycephala. Fish Shellf. Immunol., 47: 674-680. https://doi.org/10.1016/j. fsi.2015.08.022

Trippel, E.A. and Neil, S.R.E., 2002. Effects of photoperiod and light intensity on growth and activity of juvenile haddock (Melanogrammus aeglefinus). Aquaculture, 217: 633-645. https://doi. org/10.1016/S0044-8486(02)00198-9

Tuckey, L.M. and Smith, T.I.J., 2001. Effects of photoperiod and substrate on larval development and substrate preference of juvenile Southern flounder, Paralichthys lethostigma. J. appl. Aquacult., 11: 1-19. https://doi.org/10.1300/ J028v11n01_02

Turan, C., Yalcin, S., Turan, F., Okur, E. and Akyurt, I., 2005. Morphometric comparisons of African catfish, Clarias gariepinus populations in Turkey. Folia Zool., 54: 165-172.

Venables, W.N. and Ripley, B.D., 2002. Modern applied statistics, fourth ed. Springer, New York. https:// doi.org/10.1007/978-0-387-21706-2

Verreth, J.M. and Van Tongeren, M., 1989. Weaning time in Clarias gariepinus (Burchell) larvae. Aquaculture, 83: 81-88. https://doi. org/10.1016/0044-8486(89)90062-8

Wendelaar Bonga, S.E., 1997. The stress response in fish. Physiol. Rev., 77: 591-625. https://doi. org/10.1152/physrev.1997.77.3.591

Wickham, H., 2016. ggplot2: Elegant graphics for data analysis. Springer-Verlag, New York. https://doi. org/10.1007/978-3-319-24277-4_9

Wiederhecker, H.C., Pinto, C.S. and Colli, G.R., 2002. Reproductive ecology of Tropidurus torquatus (Squamata: Tropiduridae) in the highly seasonal Cerrado biome of central Brazil. J. Herpetol., 36: 82-91. https://doi.org/10.1670/00221511(2002)036[0082:REOTTS]2.0.CO;2

Wilkens, L.A., Russell, D.F., Pei, X. and Gurgens, C., 1997. The paddle fish rostrum functions as an electro-sensory antenna in plankton feeding. Proc. R. Soc. Lond. B, 264: 1723-1729. https://doi. org/10.1098/rspb.1997.0239

Y1lmaz, S. and Ergün, S., 2011. Effect of red pepper (Capsicum annum) on pigmentation of blue streak hap (Labidochromis caeruleus). Isr. J. AquacultBamid., 63: 1-6. 


\section{Supplementary Material}

\section{Influence of Photoperiod and Shelter on Some Phenotypic Traits in African Catfish (Clarias Gariepinus Burchell 1822) Larvae}

Ahmed Saud Alsaqufi ${ }^{1}$, Sheikh Mustafizur Rahman ${ }^{2,3 *}$, Roshmon Thomas Mathew ${ }^{2}$, Yousef Ahmed Alkhamis ${ }^{1,2}$, Md. Moshiur Rahman ${ }^{3,4}$ and Muhammed Aslam Pathiri ${ }^{2}$

${ }^{1}$ Agriculture and Food Sciences College, King Faisal University, Hofuf-420, Zip 31982, Al-Ahsa, Kingdom of Saudi Arabia.

${ }^{2}$ Fish Resources Research Center, King Faisal University, Hofuf-420, Al-Ahsa, Zip

31982, Kingdom of Saudi Arabia

${ }^{3}$ Fisheries and Marine Resource Technology Discipline, Khulna University,

Khulna-9208, Bangladesh

${ }^{4}$ Tokyo University of Marine Science and Technology, Tokyo, Japan.

Contribution of variables to Dim-1

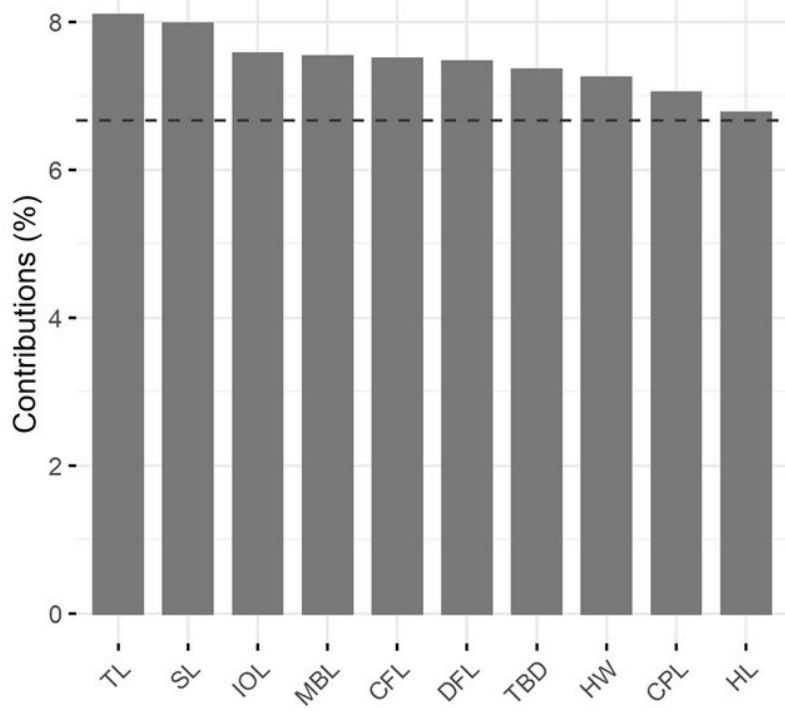

Supplementary Fig. A1. Loading contribution of different measured morphological traits in the first Principal Component (PC1) during the Principal Component Analysis (PCA).
Contribution of variables to Dim-2

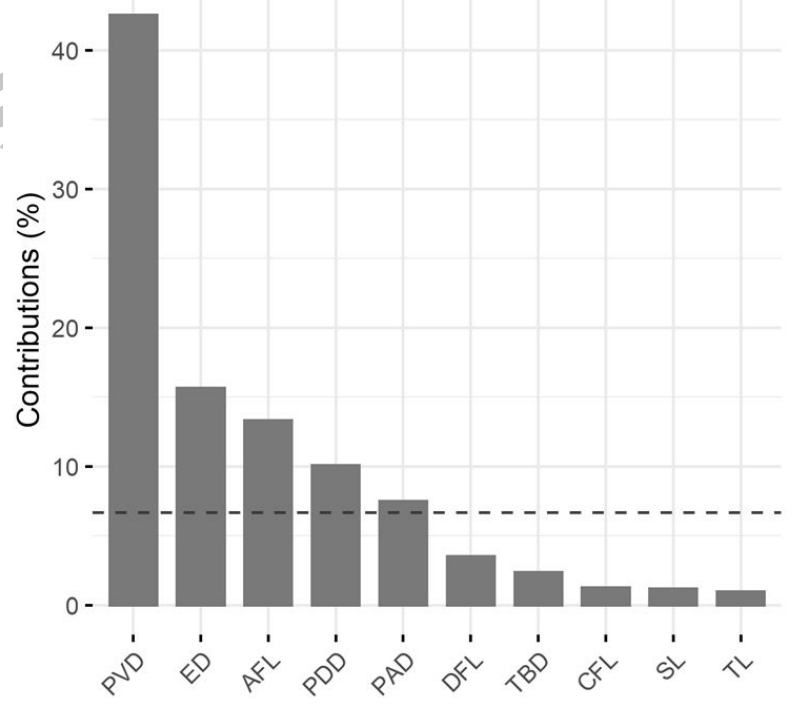

Supplementary Fig. A2. Loading contribution of different measured morphological traits in the second Principal Component (PC2) during the Principal Component Analysis (PCA).

\footnotetext{
Corresponding author: mustafizfrmt@yahoo.com, srahman@kfu.edu.sa 0030-9923/2021/0001-0001 \$ 9.00/0

Copyright 2021 Zoological Society of Pakistan
} 